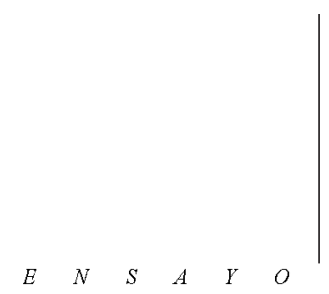

\title{
RACISMO EN LA ESCUELA CARTAGENERA
}

\section{RACISM IN CARTAGENA SCHOOLS}

* CLARA INÉS FONSECA MENDOZA

País: Colombia

Fecha de nacimiento: 5

de diciembre de 1960

Documento de identidad:

Documento de identidad:

C.C. 51636390 de Bogotá

Afiliación institucional:

Universidad de Cartage-

na. Facultad de Ciencias
Humanas

Humanas

de escolaridad:

Magíster
${ }^{1}$ Este documento forma parte del proyecto ESpacios de discriminación racial en Cartagena, aprobado por la vice-rectoría de investigaciones de la Universidad de Cartagena, mediante la Resolución 1270 del 20 de abril de 2012.

\author{
Por: Clara Inés Fonseca* \\ Recibido 20 de noviembre 2013. Aprobado 18 de febrero 2014
}

\begin{abstract}
RESUMEN
Este ensayo describe algunas formas de racismo cotidiano ejercidas en la escuela cartagenera ${ }^{1}$ y sus implicaciones en los tipos de relaciones raciales allí establecidas. Los datos son tomados de entrevistas a personas negras, quienes recordaron esas experiencias en su niñez y adolescencia y también relataron casos recientes ocurridos a sus hijos o conocidos. Se muestra que la escuela cartagenera, como institución social y como contexto local, basa sus jerarquías en el color de la piel; a partir de ello, ejerce el control social mediante formas de marginalización y de sometimiento (Essed, 1191); estas últimas son sentidas especialmente por las mujeres. Se concluye que la escuela cartagenera es un espacio permanente de confrontación racial y de negociación de la identidad.
\end{abstract}

Palabras clave: Cartagena, escuela, racismo cotidiano.

\section{ABSTRACT}

This essay describes some forms of everyday racism in Cartagena's school and the racial relations established. Data came from interviews of some members of the Black community in Cartagena who reported experiences of racism at school. As a social institution and local context, Cartagena's school promote racial relations based on skin color, by means of marginalization and containment (Essed, 1991); the last ones are specially perceived by women. As a result, it is showed that Cartagena's school is a permanent context of racial confrontation and a place to negotiate identity.

Key words: Cartagena, everyday racism, school.

\section{Introducción}

$\mathrm{E}$ ntendemos el racismo como una forma de dominación del grupo de personas de piel clara, en dos dimensiones: a nivel macrosocial y a nivel microsocial. De acuerdo al primer nivel, el racismo es ejercido por grupos e instituciones que contribuyen a la desigualdad social; por el segundo, el racismo se reproduce en la interacción cotidiana y, con ello, legitima relaciones de poder sustentadas en la raza y la etnicidad (van Dijk, 1997; Essed, 1991). Una de las instituciones en donde se registra la presencia del racismo, es la escuela. Esta, como institución social y como contexto local, puede constituirse tanto en espacio racializado como en agente racializador, en fuerza que reproduce y transforma relaciones raciales: "Although they clearly do not teach racial identity in the way they teach multiplication or 
punctuation, schools are settings where people acquire some $r$ rules of racial classification" and of their own racial identity" (Lewis, 2006: 284). En la escuela, los niños y jóvenes viven experiencias cotidianas enmarcadas en esquemas raciales que les enseñan, entre otras, cuál es su posición respecto de los otros. Es acerca de estas experiencias y relaciones -sobre los procesos de racismo cotidiano experimentados por las personas $\square \square$ r $\square \square \square \square \square \square \Pi^{2}$ cartagenera y las relaciones raciales allí establecidas-de que trata este ensayo.

\section{Metodología}

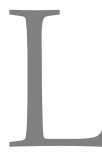

a evidencia tomada para este estudio, forma parte del banco de datos del grupo de investigación TEXCULTURA. Se trata de relatos obtenidos mediante veinte (20) entrevistas a profundidad realizadas a personas

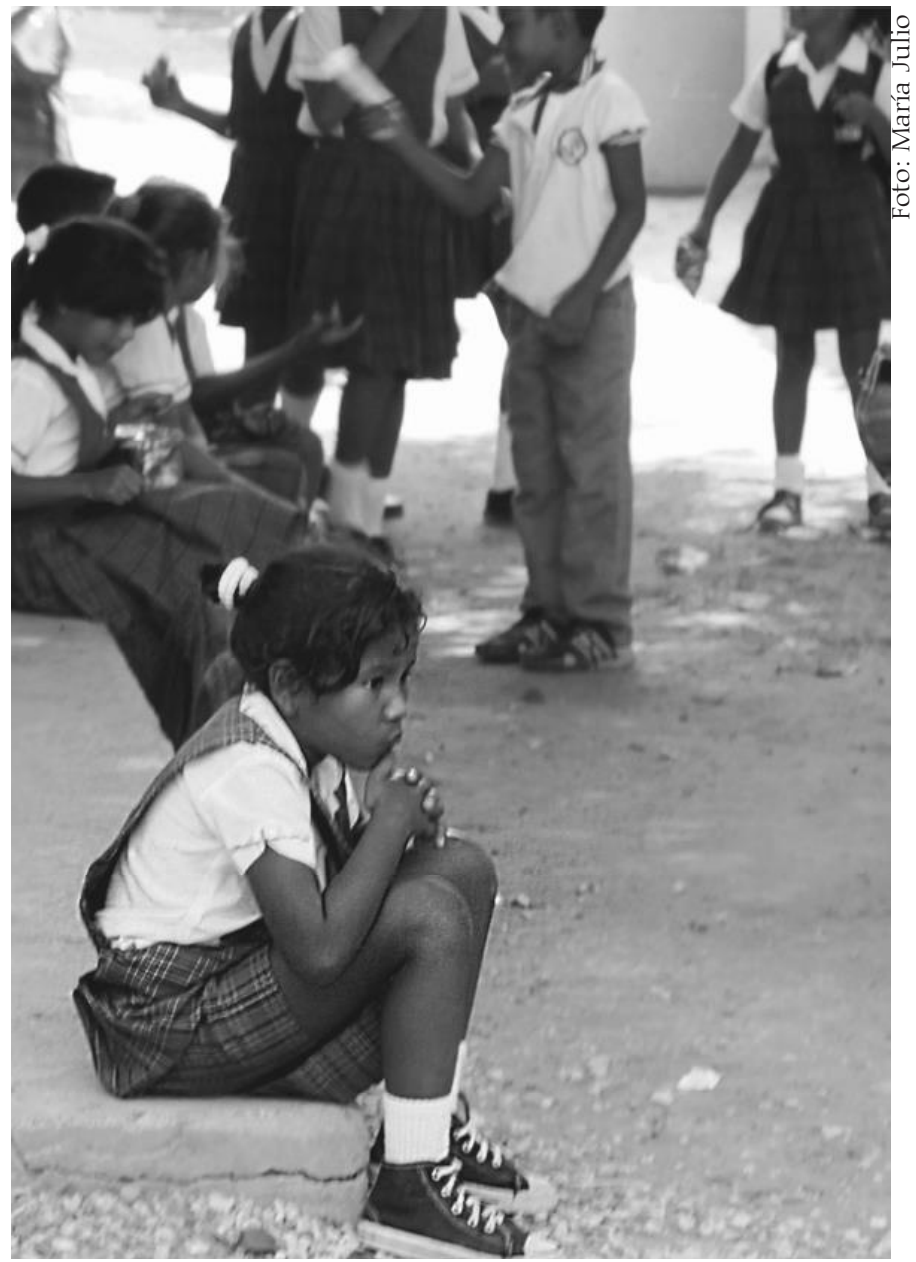
negras cartageneras, entre los años 2006 y 2009, quienes tienen la particularidad de ser conscientes del problema de la discriminación racial; según Essed (1991), esta última condición es necesaria porque solo así están en capacidad de decidir qué eventos son racializados; de este modo, los relatos, más que historias personales, remiten a experiencias de discriminación socialmente compartidas, a construcciones subjetivas de la realidad. En las entrevistas, se les solicitó narrar situaciones racistas vividas o conocidas en diferentes contextos, uno de ellos, la escuela; se obtuvo el recuerdo de personas adultas sobre su infancia y adolescencia y también el relato de experiencias recientes que han tenido los hijos o conocidos de los narradores.

Los eventos de exclusión mencionados, se organizan mediante el modelo de Essed (1991) para analizar el racismo cotidiano -biológico y cultural- acudiendo a las categorías de marginalización, problematización y sometimiento. La marginalización, crea el espacio para "el otro", refuerza el sentido de que ese otro existe y es diferente. La problematización consiste en recalcar las características y actitudes negativas de los otros, a los ojos de los discriminadores, para legitimar

${ }^{2}$ En este ensayo solo nos referiremos al nivel microsocial. No debe pasar desapercibido, sin embargo, que las denominadas comunidades étnicas están en franca desventaja en cuanto a cobertura, desempeño académico, motivación y putoestima; esto último puede colegirse del estudio de Sánchez (2011). El CONPES (2010), además, afirma que la tasa de cobertura en educación universitaria para la población negra en Bolívar es del 24,9\%. Por otra parte, con Escuela nos referimos a todos los niveles de escolaridad, actores (profesores, compañeros y comunidad escolar en general) y currículos. 
la exclusión y reprimir la oposición. El sometimiento, describe los métodos usados para justificar el bajo estatus del grupo discriminado y reprimir su deseo de obtener un estatus igual al de la mayoría.

\section{Resultados}

T os procesos de racismo llevados a cabo en la escuela cartagenera, pueden visualizarse en el siguiente cuadro; además de los procesos comunes, $ـ$ marcados en letra corriente, los experimentados solo por hombres se señalan en cursiva y, por mujeres, subrayados.

\section{CUADRO 1. PROCESOS DE RACISMO EXPERIMENTADO EN LA} ESCUELA CARTAGENERA, POR HOMBRES Y MUJERES

\begin{tabular}{|c|c|c|}
\hline \multicolumn{3}{|c|}{ MARGINALIZAR } \\
\hline \multicolumn{3}{|c|}{$\begin{array}{l}\text { Obstáculos que impiden la participación equitativa: } \\
\text { - Requerimientos adicionales } \\
\text { - No facilitar la participación } \\
\text { - Barreras } \\
\text { - No reconocer la cualificación } \\
\text { - Evitar el contacto social } \\
\text { - Ignorar }\end{array}$} \\
\hline \multicolumn{3}{|c|}{ PROBLEMATIZAR } \\
\hline \multicolumn{2}{|c|}{ Denigración biológica } & Denigración cultural \\
\hline \multicolumn{2}{|c|}{ - Purismo racial. Ser señalados 'feos' } & - Baja estima de la forma de hablar \\
\hline \multicolumn{3}{|c|}{ SOMETER } \\
\hline \multicolumn{3}{|c|}{$\begin{array}{l}\text { - Sobre-énfasis de la diferencia } \\
\text { - Segregación } \\
\text { - Etnización de profesiones } \\
\text { - Rechazo al contacto sentimental } \\
\text { - Rechazo al comportamiento étnico } \\
\text { - Fragmentación }\end{array}$} \\
\hline $\begin{array}{l}\text { Negación de } \\
\text { la dignidad }\end{array}$ & \multicolumn{2}{|l|}{ - Humillación } \\
\hline Intimidación & \multicolumn{2}{|c|}{$\begin{array}{l}\text { - Intimidación verbal (apodos, ridiculización) } \\
\text { - Violencia física } \\
\text { - Hostilidad }\end{array}$} \\
\hline Retaliación & \multicolumn{2}{|c|}{$\begin{array}{l}\text { - Autoritarismo enérgico } \\
\text { - Represalias }\end{array}$} \\
\hline Negación del racismo & \multicolumn{2}{|c|}{ - No tomar postura frente el racismo } \\
\hline Pacificación & \multicolumn{2}{|l|}{ - Patronización } \\
\hline Otros & \multicolumn{2}{|c|}{ - Sentirse observado } \\
\hline
\end{tabular}

La mayor parte de las categorías anteriores tienen un contenido proposicional transparente; no obstante puede aclararse que, por ejemplo, la marginalización crea obstáculos para acceder a los recursos materiales y no materiales; incluyen barreras para que no se entre en los dominios del otro; ignorar, por su parte, 
es tratarlos como si no estuvieran allí. En el sometimiento, la segregación consiste en separar a los grupos o a las personas de mí; patronizar es una forma extrema de opresión porque recalca la inferioridad del otro como alguien que necesita un benefactor.

El inventario del cuadro 1 indica rasgos prominentes de las formas de racismo percibidas por las personas negras en la escuela cartagenera; se trata de procesos de problematización, marginalización y sometimiento que hacen de la escuela, para muchos estudiantes negros, un lugar para la confrontación. Veamos en detalle esas formas, ilustradas con evidencias narrativas de los entrevistados.

\section{La apreciación estética como trasfondo de la marginalización y el sometimiento}

En el cuadro 1 se señala que tanto los hombres como las mujeres entrevistados, estuvieron de acuerdo en que sus experiencias en la escuela tenían la misma raíz problematizadora: su forma de hablar fue objeto de algún tipo de señalamiento y se percibieron descritos como 'feos'. Son dos características que aluden a valores negativos de apreciación estética; Martin y White (2005: 45) describen estas valoraciones como "institutionalised feelings, which take us out of everyday common sense world into the uncommon sense worlds of shared community values". En estos términos, sobre la forma de hablar de las personas negras y su apariencia física se formulan juicios apreciativos basados en escalas de valores socialmente adquiridas. La diferencia estriba en el referente evaluado; el primero es una entidad: se denigra de un objeto cultural: el habla. El segundo referente lo constituyen las personas de quienes se denigra biológicamente.

\section{-La actitud lingüística ante la lengua palenquera}

La actitud lingüística puede definirse como las reacciones evaluativas de los escuchas ante las variaciones del habla (Cargile y Bradac, 2001); la importancia del tema radica en que las valoraciones de una lengua pueden contribuir a su permanencia o su desaparición ${ }^{3}$. La palenquera es una lengua de acento tonal y no de acento dinámico, como el español: "la sílaba acentuada se realiza por medio de un tono de nivel alto y la inacentuada por un tono de nivel bajo" además algunos investigadores "sostienen que la duración es, en algunos casos, también un correlato del acento" (Portilla, 2009: 150). Esta diferencia es la que el "otro" nota y por la cual estigmatiza el habla de las personas de Palenque; esos otros son tanto las personas de piel clara como las personas negras no palenqueras.

Palobra No. 14. Agosto de 2014
${ }^{3}$ En reciente encuesta del Ministerio de cultura, se determinó que el 32,1\% del pueblo pa lenquero, no lenquero, no habla ni entiende la lengua pawwW.mincultura.gov. co/?idcategoria $=43152$ 
${ }^{4}$ Bajo este recurso de nota al pie, identificamos, con seudónimo, a los entrevistados. Liseth: investigadora de la cultura de Palenque Profesora en el Distrito de Cartagena. ${ }^{5}$ Daysi: líder comunitaria. ${ }^{6}$ Ana: profesora.
La forma de hablar puede constituirse en objeto de burla y, con ello, de humillación; Liseth ${ }^{4}$ cuenta el caso de Yoli, una estudiante universitaria palenquera, que debía hacer prácticas pedagógicas en un colegio; pues bien, la profesora titular del aula a donde fue enviada, se burlaba de su acento; al ver esto, los pequeños alumnos "remedaban el cantadito de Yoli". Ella no se quejó ante ninguna autoridad por el temor a las represalias; Liseth interviene y el caso se cuestiona en la rectoría pero sin mayores consecuencias a largo plazo (solo se cambia de sitio a Yoli). Se da a entender que la institución escolar cartagenera no está interesada o preparada para enfrentar el problema.

\section{-El color de la piel y la forma del cabello como marcadores de exclusión}

Históricamente, las ideologías de 'lo bello' se han definido en contra de la población negra (Mercer, 1987); el concepto blanco-centrista de belleza riñe con, al menos, dos características fisiológicas de las personas negras: el color de la piel y la forma y textura del cabello, precisamente los objetos corporales que constantemente han sido expuestos a manipulación ideológica. Los entrevistados asociaron belleza y color de piel para explicarse por qué razón eran marginalizadas de las diversas actividades culturales llevadas a cabo en las instituciones ("escogían siempre a las muchachitas más... las blanquitas (...) 'las más bonitas', decían" -Daysi ${ }^{5}$-); la causa no era atribuida a carencia de capacidades personales ("y muchos de nosotros teníamos cualidades y aptitudes, talento para eso de la poesía, para el canto, para esto, y casi nunca a nosotros nos cogía" -Ana ${ }^{6}-$ ), sino a motivos raciales.

En Cartagena, la ecuación blanco=bello se renueva cada año en el reinado nacional de belleza en donde la más 'bella' resulta ser una blanca, mientras que reservan el 'reinado popular' para elegir una cartagenera (que cada vez es más clara); además "aunque oficialmente el concurso de belleza no tiene color, sigue siendo la vitrina de un país que tiende a relacionar identidad nacional con blancura" (Cunin, 2003: 167). Cabe señalar que dos de las entrevistadas, comentaron sobre la realización de reinados de belleza en el colegio en donde no se les permitía participar; una de ellas, incluso, refirió que otra compañera 'blanquita' realizaba un reinado con solo niñas negras.

El color de la piel fue la causa por la cual varios de los hombres y mujeres entrevistados hicieron referencia a la obligación que sentían de exigirse intelectualmente, mucho más que sus compañeros, por lo que la competencia académica les resultaba una suerte de requerimiento adicional; en ninguno de los casos se trataba de suplir una falta intelectual sino, precisamente, una 
respuesta a la marginalización y el sometimiento. La situación vivida en la escuela primaria y secundaria no cambia en la Universidad. Ana, por ejemplo, relata el modo como los estudiantes blancos cuestionaban la presencia de negros en la Universidad mediante expresiones como 've, el negro este, la negra esta'. Ante estas formas de segregación, una de las respuestas era la de agruparse ("dentro del aula de clase y dentro de los trabajos de campo, ellos estaban por un lado y nosotros por el otro -Ana-" "Lo llaman a uno 'negro'; le dicen 'negra' y uno siempre intenta es de agruparse con las personas que tengan de pronto su mismo color (...) y hacer mi trabajo en grupo y todo con esa persona que es negra igual que yo" -Carmen ${ }^{7}$-)

Pero, las agresiones verbales en la escuela provocan dolorosas reacciones en quienes las reciben; como ejemplo de ello, Misael $^{8}$ cuenta (también con gran pesar) lo ocurrido con su hijo en el primer año de la secundaria:

Estando en el (...) primer año de bachillerato, una tarde me llamó; yo fui a buscarlo al colegio y... eh... pues estuvo callado todo el tiempo; $y$ yo: ' ¿qué te pasa?' Me dijo: 'no, no' estuvo calla'o; 'allá te cuento en la casa'. Cuando llegamos a la casa, pues se desvistió, se puso su pantaloneta; me dijo: 'papi no vuelvo más al colegio'. Digo 'ipor qué?' Me dice: 'no, no, no, es que allá mis compañeros me dicen 'ese negro, ese negro, ese negro es bruto; ee ese negro, no sabe oye negro" Lo, lo, lo gritaban y entonces él... se...ee... se cohibía incluso de jugar con ellos.

- ¿Y cuál era la reacción de su hijo cuando, cuando esos compañeros le decían que él era negro? ¿qué hacia él?

- Se ponía a llorar; se ponía a llorar.

Ana cuenta la pesadumbre de su hijo cuando le cuenta que en el colegio le dicen 'negrito' y 'chocolatico'. Como lo señala Essed el apelativo 'negro' y todos los demás epítetos que lo relacionan, son conceptos que representan una historia de opresión; los apodos y todo tipo de intimidación verbal remarca esta historia.

Por último, los hombres revelan en las entrevistas el temor del grupo ${ }^{7}$ Carmen: profesora. dominante porque ellos se les acerquen más de lo debido, lo que sucedería si mantiene algún tipo de contacto amoroso con sus mujeres: "a las pelaítas no le gustaban los negritos que tenían el pelo así como el mío" (Adolfo ${ }^{9}$ ). Carlos ${ }^{10}$ relata un episodio aún más extraño: cuando estudiaba en Bogotá, se ennovió

${ }^{8}$ Misael: profesor universitario.

${ }^{9}$ Adolfo: profesor universitario.

${ }^{10}$ Carlos: periodista y líder social. 
Sobre este tema puewWW.eltiempo.com Multimedia/galeria_fotos/carrusel/palenqueun-pueblo-tejido-en- con una muchacha "mestiza con unos rasgos, inclusive, indígenas" pero el padre de la novia no estaba de acuerdo, al punto de que prefería llevarla a la casa de Carlos para que este no fuera a la de ella.

Adolfo y Carlos, por su parte, plantean otro modo de ver los procesos de marginalización por el color de la piel, esta vez referido a lo poco probable que es acceder a la Escuela Naval de Cadetes o a un colegio como el George Washington; cabe anotar que los obstáculos que se perciben para ingresar a instituciones como estas, se sienten como barreras que, aunque no son visibles (por ejemplo, no está estipulado en los manuales de ingreso) se conocen, al punto de poder hablar de ellas:

Si tú te presentas a la escuela de cadetes, puede que pases tu examen, más todos los que están ahí; pero no entras. Por dos razones: porque eres pobre y porque eres negro, pero más por esto último; porque el pobre teniendo los cinco millones de pesos aún puede entrar, pero el negro ni teniendo cincuenta (comentario citado por Adolfo).

En estos casos, la marginalización opera no como factor de clase o dinero, sino de color de piel como factor de diferencia.

\section{"La cuestión del cabello"}

Aún más que el color de piel, el cabello constituye una de las causas de conflicto más frecuentes en la escuela primaria; el tema es mencionado tanto por hombres como por mujeres pero son estas últimas quienes ofrecen mayores detalles y evaluaciones. Para las mujeres en general, el cabello se propone como parte de su feminidad pero, además, para mujeres y hombres, como parte de la raza; es decir, el cabello en las mujeres negras en sociedades racistas se torna en un elemento de discriminación por raza y por género: "Of all the physical characteristics, it is particularly hair that marks "race" for women... It is in the issue of hair that one sees a distinction between men and women and the differential social coding of race and ethnicity" (Gilliam and Gilliam (1999), citadas por Caldwell (2004)). El color de la piel y el cabello adquieren significados positivos/negativos organizados en sistemas clasificatorios polarizados alrededor de la unidad básica blanco/ negro: bueno/malo; bonito/feo; superior/inferior; dominante/dominado. Ante esto y respecto al cabello, las mujeres especialmente, han ofrecido dos tipos de respuestas: alisar sus cabellos o recrearlos con peinados elaborados ${ }^{11}$ : afros, trenzados, moños y extensiones. 
La idea de si alisarse el cabello tiene o no que ver con la pérdida de la identidad o con asimilar la cultura del blanco y negar la propia, es discutida por varios autores (Mercer, 1987; Hook, 1988; Caldwell, 2004); se reconoce que los contextos socio-político e históricos específicos, conducen a respuestas diferentes de las personas negras en cuanto a los significados sociales y personales de la belleza en relación con el cabello; en este sentido, las dos opciones antes mencionadas no se someten a discusión; alisarse el cabello, por ejemplo, no es un modo de querer parecerse al blanco, es simplemente eso: un modo de llevar el cabello. No obstante, como lo veremos, este discurso se reinterpreta frecuentemente en la realidad cotidiana de las escuelas cartageneras.

Los entrevistados refieren diferentes historias alrededor del cabello, haciendo de este un tema recurrente; Mileydis ${ }^{12}$ no relata con detalle lo que le ocurrió en la escuela primaria o secundaria, pero lo resume diciendo "yo me acuerdo que... bueno, lo que más sufre uno de negro cuando es pequeño y va al colegio, es la cuestión del cabello"; ella, ahora que es mayor, percibe el mismo conflicto con sus hijas y familiares pequeñas ("las amiguitas hacían grupos y (...) la excluían de los juegos") y lo evita alisando sus cabellos a petición de las mismas niñas, a los ocho años de edad. No obstante, la diferencia seguirá siendo prominente porque supone el estándar comparativo con el Blanco (Essed 97); tal vez por ese motivo Mileydis añade que la búsqueda de aceptación no cesa; su pequeña familiar "le exige mucho a la mamá (...) el mejor bolso... que tiene que ser la mejor vestida..."

Daisy se queja que recibió trato discriminatorio en la escuela aunque tenía una ventaja que ahora también tiene una hija suya: su cabello es liso; por esta razón, según ella, su hija no lo recibe. Merly ${ }^{13}$ centró su entrevista alrededor de su cabello liso y de las ventajas que esto le generaba dentro de su familia, entre ellas, la de ser considerada bonita, inteligente y no apta para ciertas prácticas propias de persona negras como bailar. Esta condición la llevó, incluso, a formar parte de 'los victimarios'; en efecto, ella cuenta el siguiente caso de intimidación verbal (seguramente acompañada de violencia física) hacia una compañera negra en el colegio:

Por el pelo, si, entonces como a ella su abuelita le hacía dos trenza aquí, dos trenzas gordísimas, porque tenía mucho pelo y bien rucho, entonces le hacían dos trenzas aquí y nosotros le decíamos... este... Como... le decíamos... 'mojón de no sé qué cosa'... Que... 'tus moños parecen unos mojones de no sé qué cosa ' - no me acuerdo de qué animal-y le decíamos 
que 'tus moños son dos buques', algo así, nos poníamos con cosas así.

Esta actitud extrema de Merly puede explicarse como un caso en que "el discurso del poder es sostenido por sus propias víctimas" (Reboul, 1986: 102), o bien puede tratarse de un recurso para desviar la atención de los otros y de este modo no ser blanco de agresión. Varios narradores relataron casos similares, es decir, de niños negros que reciben muestras hostiles de otros niños negros, aludiendo a su cabello, sus rasgos físicos o a su forma de hablar.

El cabello no fue tema de mención exclusivo de las mujeres; los hombres también se refieren al él; Adolfo describe su cabello como "mesón lleno de pimienta de olor" razón por la que no podía hacerse "el cortecito, el honguito" y por eso no era preferido entre las muchachas. Añade, además que también las profesoras participaban de las que consideraban bromas a los niños por su apariencia física. Carlos, por su parte, presenció una arista diferente del conflicto: peleas entre compañeros varones debido a "quién tenía el cabello más, más liso o menos, menos rucho, menos apreta'o, (...) era una discusión de quién era más negro o quién era menos negro; y eso se estaba yendo (...) casi a la agresión física".

La mayor parte de los entrevistados no relataron formas de reacción a las agresiones y conflictos que se han señalado en este trabajo; muchos de ellos consideraban que se trataba de una situación normal, muy a pesar de las consecuencias penosas que pudiera tener. Cuando ocurrió lo contrario, es decir, cuando intentaron levantar una voz de protesta, recibieron formas extremas de sometimiento, algunas de ellas expresadas en retaliaciones. Ese fue el caso del niño que le reclamó al profesor por su comportamiento agresivo hacia él; el profesor le respondió diciéndole "cállese, negro"; ante esto, el niño no dijo nada, incluso, a raíz de esto recibió la burla de sus compañeros; pero él no dijo nada "porque no quería volverme violento, porque además que era negro y me ponía violento pues me iba a ir peor" (de un caso relatado por Merly).

Por otra parte, y como ya lo mencionamos, algunas mujeres negras eligen llevar extensiones en el cabello; pues bien, Ana cuenta una historia ocurrida en un colegio de Rocha, uno de los corregimientos de Arjona (población cercana a Cartagena) en donde:

Las niñas no pueden hacerse sus peinados afros (...) [Por ejemplo] cada vez que Alia llevaba ese peinado la devolvían. Le dijeron una vez (... 'La 


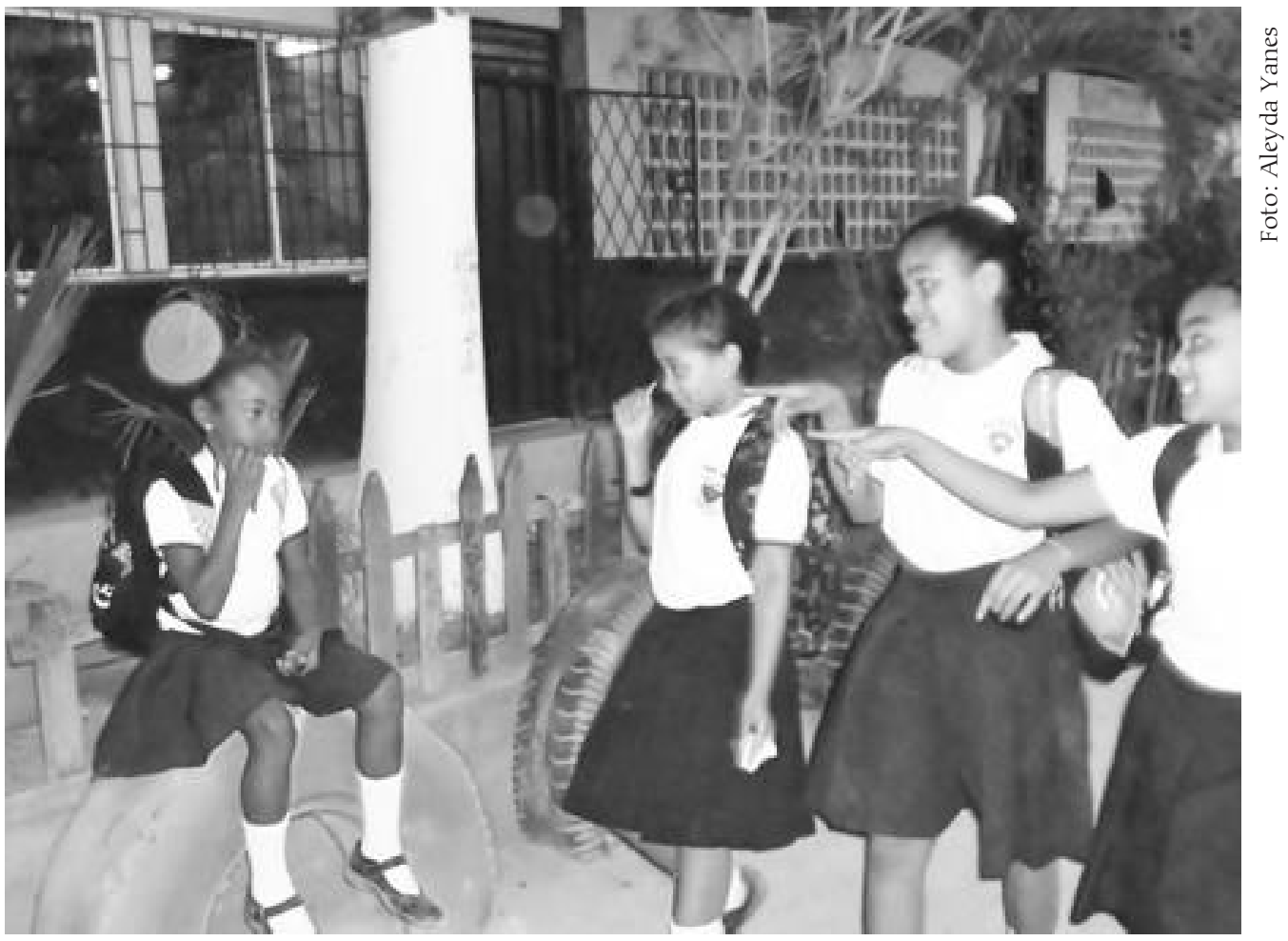

próxima vez, tienes matrícula condicional ${ }^{14}$. Y el lunes siguiente fue con el cabello alisado (...) el rector y muchos profesores [le dijeron] -'Mira cómo te ves de bonita'

La elección de Alia constituyó para las autoridades escolares un comportamiento étnico que ellos rechazaron con amenazas de retaliación. De nuevo, se trae a colación la dicotomía bonito/feo asociado al cabello. Curiosamente, los peinados étnicos rechazados en ese colegio, se han convertido en productos culturales que, en cambio, son acogidos por personas negras del Pacífico, en otras ciudades, como Bogotá (Rodríguez, 2006) e incluso, por los "blancos" que lucen rastas.

Un caso algo similar le ocurrió a una estudiante de una universidad del sector privado, a quien el celador no le permitía la entrada por ir calzada con sandalias aunque, al mismo tiempo, entraban las estudiantes de piel clara con ellas puestas. Protestar por la forma como el 'otro' lleva el cabello, habla o calza, puede parecer extremo; pero, como lo menciona Essed (173), el racismo permea las más pequeñas situaciones de la vida diaria, al punto en que dejan de ser insignificantes y adquieren dimensiones sociales que marcan diferencias. Veamos, precisamente, esa intromisión del racismo cotidiano experimentado en la escuela, por una persona en particular.

${ }^{14}$ Esto se dijo ampaConvivencia del colegio. Los manuales de convivencia de varios colegios de Cartagena prohiben llevar al colegio "modas extrañas en el corte de travagantes". 


\section{Liseth: agresión y oposición}

El racismo cotidiano implica, ante todo, enfrentar experiencias de este tipo en la 'vida real' y, de ser posible, oponerse a ellas. En la escuela, se identifican experiencias, tanto de opresión como de oposición, que involucran a quien percibe esas experiencias con, al menos, sus compañeros y profesores; son estos quienes llevan a cabo acciones concretas de discriminación. Entonces, conocer la experiencia específica de uno de esos actores puede aportar "una aproximación máxima a los hechos realmente experimentados" (Appel, 2005: 5); hemos elegido a Liseth. Ella, como la mayoría de los demás narradores, cuenta sus experiencias autobiográficas con cierta secuencialidad histórica y narra sucesos racializados que seguramente fueron claves en su vida (Cfr. Appel, op.cit.: las coerciones narrativas).

Además, ella conoce el contexto histórico y social de Cartagena y esto le permite organizar sus experiencias en el micronivel; por ejemplo, ahora reconoce que los eventos de racismo que creía normales, en realidad no lo eran. Como lo menciona Essed, las experiencias de racismo son acumulativas; ello permite que las nuevas se interpreten y evalúen en el marco de experiencias tempranas (como las sentidas en la familia y en el colegio) y del conocimiento general que se tenga del racismo en la sociedad. En este marco, la siguiente es una reconstrucción de la trayectoria biográfica de Liseth en la escuela.

1. Los encuentros de Liseth con el racismo comienzan desde temprana edad. El cabello es la primera fuente de conflicto y los compañeros del colegio los principales agentes de ese conflicto. Una consecuencia de esa situación es que Liseth cuestiona su identidad.

2. Sólo finalizando su vida en la escuela secundaria y, en parte de nuevo asociado a la forma de llevar el cabello y a la disposición de algunos profesores, Liseth da muestras de oposición a los comportamientos racistas de sus compañeros.

3. No obstante, al ingresar a la Universidad, dos profesoras reviven los conflictos que hacen que Liseth experimente "volver a ese ejercicio de negación del ser".

4. Pero, de nuevo, Liseth da muestras de su talante luchador e inicia un camino, en el que está ahora, como agente de oposición a las prácticas de discriminación racial en Cartagena.

Liseth comienza su relato contando las que podemos llamar "sus aventuras 
de horror por sus trenzas y moños", pues se trata de sucesos extraños y violentos que por ellos vivió en la escuela; veamos un fragmento de uno de sus relatos relacionado con sus experiencias racializadas en la escuela:

Creo que hay más estigmatización en algún momento de... de sobre todo en la niñez y en la adolescencia si tu eres negro de Palenque ${ }^{15}$ (...) La mayoría de las niñas (...) te molestaban mucho por tu peinado (...) te daban muchos cocotazos...te pegaban (...) que 'ves a peinarte tu rucho' (...) o 'cejas de diablo' (...) 'ceja rucha', 'ceja e diablo', 'ya se levantó el sol' (...) A esa hora nadie quería trabajar conmigo en... nadie quería hacer trabajo en grupo conmigo, ósea po 'que 'ya se levantó el sol y me va calentá" o... o "Poncio Pilato me va puyar con su [risa], con su (...) con su ramita de olivo'16 (...)'tonces en la, la primera etapa de la adolescencia y en... en cierto momento de la niñez, esa esa situación generó como que bastante conflicto eee...en mí; incluso este... no, no quería ser palenquera, porque es que era... esa era una burla (...) no todas las niñitas te querían hablar, te decían 'palenquerita hueles a pesca'o' y cosas así te puyaban $y$ / este... 'las vende platanito' por decirles algo.

Las confrontaciones de Liseth con el racismo suceden en el barrio y en la escuela (dos espacios también relacionados por otros entrevistados en los que, según ellos, a los niños y adolescentes les ocurrían asuntos similares). Seguramente no por azar, se enfatiza en el tema del cabello. El que la madre de Liseth enviara al colegio a su hija luciendo sus peinados 'étnicos' ${ }^{17}$ fue uno de los desencadenantes de las varias formas de sometimiento registradas en su relato anterior: intimidación por medio de la violencia física, la asignación de apodos y otras formas de acoso verbal; marginalización, cuando sus compañeras evitaban su contacto; seguramente, humillación al ser objeto de burla.

Las expresiones y comportamientos racistas pueden interpretarse como un llamado al orden, a ocupar el lugar que le correspondía: Liseth, como mujer negra palenquera, debía estar en su oficio de ventas callejeras (como aún hoy lo hacen muchas de ellas): "Si la diferencia racial es aceptada, si el otro encuentra su lugar en la ciudad, es porque está en un espacio limitado, predefinido y reservado" (Cunin, 2003: 180). Los padres quisieron revertir la situación: "mi mamá nunca quiso, ni se le cruzaba la remota idea de que nosotras vendiéramos (...) mi papá siempre estuvo en la expectativa de que no repitieran el modelo de que no repitieran el modelo e insistía mucho en eso". Ese acto de resistencia ocasiona las formas drásticas de sometimiento

${ }^{15}$ Liseth hace referencia a la pugna, a la que hicimos referencia, entre personas negras cartaeneras y personas Neconfirmamos en otras ntrevistas: por ejemplo Mileydis afirma que estos son "otra clase de negro (...) que no han mejorado

${ }^{16}$ Liseth describe los peinados que su mamá le gio' esas grandes trenzas y moñitos, se empezaba a deshacer en el trans curso de la mañana, y de allí las expresiones como se levantó el so

${ }^{17}$ No deja de parecer un eufemismo esta apreciacuenta Liseth y otras mujeres entrevistadas os moños y las trenzas gruesas eran el único modo de mantener e decir en cierto lugar. Es un 'peinado étnico' sino una forma práctica de llevar el cabello. 
${ }^{18}$ Una comentario similar expresó Carlos en una parte de su entrevis cerda pero porque soy así, negro"

${ }^{19}$ Carlos y Misael también hacen alusiones tangenciales a este tema, que puede considerars experimentadas por Liseth. No es gratuito, entonces, que Liseth concluyera que "no, no quería ser palenquera, porque es que era...esa era una burla...18

La situación de Liseth cambia en el grado 10; pero, acogiendo una suerte de requerimiento adicional impuesto por la sociedad racista que consistió en esforzarse por ser una estudiante académicamente destacada: "siempre encontré niñitas que se burlaban de mi; pero en diez y en once académicamente en el colegio se empezó a mostrar una Liseth que era competitiva con el resto de la gente". Así concluye su educación secundaria e ingresa a la Universidad. Allí, Liseth encuentra a dos profesoras que, en parte, le hacen desandar el camino. Una de ellas hacía menciones burlonas a dos representaciones fosilizadas de la cultura negra y palenquera (y algunos dirían que costeña): las supuestas pereza de las persona negras y el 'potencial sexual' de los hombres ${ }^{19}$. Ante lo primero, Listeh comenta: "y a mí me daba piedra porque yo veía a mi papá todos los días ir a trabajar, y a mi mamá trabajar"; ante lo segundo: "y eso generó que me molestaran en el salón de clase". Liseth era una de las pocas estudiantes negras de la Universidad y su molestia seguramente se debió a que se sintió blanco de los estereotipos. La otra profesora hacia marcada diferencias entre "su sociedad" a la cual se refería "en términos elevados" y la sociedad negra de la cual "hablaba en términos como que peyorativos" $\mathrm{y}$, en ocasiones, con actitudes patronizadoras. Liseth añade a su relato de las profesoras: "yo acabo de llegar a la Universidad, tengo dieciséis años; hay cosas que uno no entiende mucho de esto, 'será por mi imaginario, por mis miedos' (...) eso me hizo en algún momento otra vez volver a ese ejercicio de negación del ser (...) fue como que un momento de crisis"

Esas experiencias, le sirvieron de soporte para ser lo que ahora es:

Muchas cosas y las actividades que en la actualidad realizo van apun, apuntando a eso, es decir que de alguna forma, todas esas vivencias negativas y experiencias no muy gratas han hecho que se reafirme esa posibilidad de trabajar por lo mío. Estoy más convencida de mis elementos identitarios y soy una fascinada a mi cultura pero... no fue tan fácil llegar a esta... a esta claridad; en este momento o sea fueron momentos de crisis bastante considerables.

Por otra parte, merece mención especial la historia de Lili; ella es una alumna de Liset que es contantemente agredida de modo verbal en el colegio ("Lili la pichón de golero (...) Lili la bemba colorá") ante lo que la niña reacciona de 
dos formas: con violencia ante sus compañeros y con reclamos airados a su profesora Liseth porque:

Seño tu nos has explicado un poquito sobre la diversidad sobre la... el respeto y valoración del otro (...) Pedrito, me están diciendo así, así, así. Tú me tienes que ayudá' porque ya le he dicho a la profesora de grupo, a la seño Cení, y no me ha para'o ni cinco de bola; y entonces pa' que tú hablas tanta cosa y aquí no haces nada.

Liseth confiesa que se queda sin argumentos ante el reclamo de Lili; esta, por su parte, recibe de sus compañeros más agresión cuando les reclama; como lo señala Liseth: "y pelea y entre más tú peleas y más te pongas brava, más molestan los muchachos, más te agraden más te... te mortifican". La agresión es una de las más fuertes expresiones de sometimiento cuando logra el efecto de neutralizar la acción.

Liseth nos muestra la rudeza de la socialización racial en la escuela cartagenera y la necesidad de negociar constantemente la identidad; alguien podría decir que la suya es una historia ejemplar por su lucha contra las formas de opresión, pero esto es legitimar las inequidades estructurales y las prácticas cotidianas de exclusión. No, la de Liseth es la historia corriente de una persona en una sociedad no democrática como la cartagenera, que basa sus jerarquías en el color de la piel y en la posición social.

\section{Conclusiones}

l objetivo de este estudio fue dar a conocer el tipo de relaciones raciales establecidas en la escuela cartagenera, mediante una descripción de las formas de racismo cotidiano experimentadas allí por las personas negras. Las evidencias fueron tomadas en entrevistas a adultos que recordaron su paso en la escuela y que también relataron la situación de sus hijos y de niños o jóvenes conocidos. El resultado general es que la escuela cartagenera es un espacio permanente de confrontación y negociación de las relaciones raciales. Los niños y jóvenes experimentan todas las formas posibles de racismo cotidiano desde su marginalización de actividades propias de la escuela hasta formas extremas de violencia. La negociación incluye estrategias diversas: no reaccionar, esconder la pena, alisarse el cabello, agruparse, alertar a los hijos y confrontar al victimario.

Hombres y mujeres (en estricto sentido, niños, niñas y jóvenes) son objeto 
de flagrantes formas de exclusión en la escuela cartagenera; al respecto, las entrevistas mostraron las biografías de casi dos generaciones de estudiantes que sufrieron y sufren ahora este flagelo; calculamos que Merly y Carlos fueron estudiante entre 1975 y 1987; Liseth y Adolfo entre 1980 y 1992; las hijas y primas de Mileidys, y Lili (la alumna de Liseth) hoy (2013) son estudiantes de secundaria. Los agentes promotores del racismo mencionados por los narradores fueron sus compañeros, en primer lugar, y sus profesores. Los compañeros pueden ser niños o jóvenes tanto de piel clara como de piel negra. Pero, la responsabilidad de los profesores ${ }^{20}$, es mayor no solo por la acción sino por la inacción; en las entrevistas vimos que ambas formas son llevadas a cabo perniciosamente por estos actores, por cuanto, o bien fomentan o bien son silenciosos ante el racismo en la escuela; decimos, con Essed (42) que su responsabilidad es mayor porque, precisamente por su relación de jerarquía, influyen en los puntos de vista de los otros; esta influencia puede ser la de resistencia, la de protestar contra el racismo, como lo hace Liseth y lo hicieron algunas de sus profesoras en la secundaria.

Las mujeres son las más expuestas, es decir, las que mayores formas de discriminación reciben; tal vez esto se debe, por una parte, a que ellas deben lidiar con la raíz problematizadora de la exclusión, esta es, la de la apreciación estética y sus consecuencias en los cánones de belleza, en donde opera la ecuación blanca + cabello liso $=$ bonita. Por otra parte, y como lo demuestra las mayores trazas de sometimiento de que son objeto, porque, posiblemente, las mujeres son quienes más muestras de oposición directa e indirecta hacen al racismo en la escuela. En esta dirección, la actitud de estudiantes como la de Lili, es un llamado a que se entienda que aunque las prácticas discriminatorias son reiteradas (cotidianas), esto no constituye la situación normal: "Acknowledgment of this critique can only mean that fundamental norms, values, and the existing social order must be questioned and subjected to change" (Essed: 282). La escuela es el lugar ideal para esa transformación.

${ }^{20} \mathrm{Cabe}$ señalar que en las entrevistas solo se menciona un profesor; las demás son profesoras; este dato puede ser posteriores. 


\section{BIBLIOGRAFÍA}

Apple, M. (2005). La entrevista autobiográfica narrativa: fundamentos teóricos y la praxis del análisis mostrada a partir del estudio de caso sobre el cambio cultural de los otomíes en México. Forum: Qualitative Social research (on-line journal), 6 (2), Art. 16. Disponible en: http://www. qualitative research.net.

Caldwell, K. (2003). "Look at her hair": the body politics of black womanhood in Brazil. En: Transforming Anthropology. Vol. 11. Issue 2.

Cargile, A. and Badrac, J. (2001). Attitudes toward language: a review of speaker-evaluation research and a general process model. En: Communication Yearbook 25.

Consejo Nacional de Políticas Económica y Social. (2010). CONPES 3660 de 2010. Política para promover la igualdad de oportunidades para la población negra, afrocolombiana, palenquera y raizal. Bogotá. En: https://www.dnp.gov.co/LinkClick.aspx?fileticket=oqFauhEG1C4\%3D\&tabid=273

Cunin, E. (2003). Identidades a flor de piel. Lo "negro" entre apariencias y pertenencias: categorías raciales y mestizaje en Cartagena. Bogotá: Arfo Editores.

Essed, Philomena. (1991). Understanding everyday racism. An interdisciplinary theory. Newbury Park, California: SAGE publications.

Hook, B. (1988) Straightening our hair, Zeta magazine. Trad. Desiderio Navarro, http:// negracubana.nire-blog.com)

Lewis, A. (2003). Everyday Race-Making. Navigating racial boundaries in schools. En: american behavioral scientist, Vol. 47 No 3, November, 283-305.

Martin, J.R. and White, P.R.R. (2005). The language of evaluation: appraisal in english. London: Palgrave.

Mercer, K. (1987). Black hair/style politics. En: new formations NUMBER 3 WINTER.

Portilla, M. (2009). Tono y acento en el pidgin afroportugués americano. En: Filología y Lingüística XXXV (1): 139-177.

Reboul, O. (1986). Lenguaje e ideología. México: F.C.E.

Rodríguez, N. (2006). Estado del arte de la investigación sobre las comunidades de afrodescendientes y raizales en Bogotá D.C. Bogotá: Alcaldía Mayor de Bogotá. Instituto Distrital de Cultura y Turismo.

Sánchez, A. (2011). Etnia y desempeño académico en Colombia. En: Documentos de trabajo sobre economía regional (156). Cartagena: Banco de la República.

Van Dijk, T (1997). Historias y racismo. En: Dennos Mumby (comp.), Narrativa y control social. Perspectivas críticas. Buenos Aires: Amorrortu, 1997. 